\title{
A BACTERIOLOGIC STUDY OF THE FACTORS AFFECTING THE EFFICACY OF STREPTOMYCIN THERAPY OF URINARY TRACT INFECTIONS ${ }^{1,2}$
}

\author{
By GEORGE T. HARRELL, E. GARLAND HERNDON, JR., CHARLES M. GILLIKIN, \\ AND JERRY K. AIKAWA
}

(From the Department of Internal Medicine, Bowman Gray School of Medicine of Wake

Forest College and the North Carolina Baptist Hospital, Winston-Salem, North Carolina)

(Received for publication December 9, 1946)

Streptomycin appears to be the most useful antibiotic available at present for the treatment of infections due to gram-negative bacilli. The absorption, distribution, and excretion of the drug following various modes of administration have been studied (1). The results of clinical trials of the drug in various types of infections have been reported (2). Treatment schedules and the influence of various factors in determining the optimum dosage of streptomycin have been investigated clinically, and the results are being reported elsewhere (3). The observation that the most common cause of therapeutic failure was the development of bacterial resistance or fastness ${ }^{8}$ to streptomycin focused attention on the necessity for further bacteriologic studies in relation to concentrations of streptomycin. The cases of urinary tract infection afforded an opportunity for further investigation of the effect of streptomycin on bacteria.

\section{MATERIALS AND METHODS}

\section{Bacteriologic methods}

In each case an attempt was made to detect all the flora involved. Urine was collected by catheterization in all females and in many of the males; in the remainder of the males voided specimens were collected after thorough cleansing of the glans and meatus with a 1:1,000 solution

1 The streptomycin used in this study was furnished by the Committee on Chemotherapeutics and Other Agents of the National Research Council.

2 These studies were aided by a grant from Miss Edith Pipkin and Mrs. J. B. Pipkin.

8 Although the term resistance has been used to denote a lack of response by the organism to the drug, the possibility of confusion with resistance (immunity) of the host would suggest that another term such as insensitivity, refractoriness, fastness, or non-susceptibility should be used when referring to the bacteria. Refractoriness or fastness would imply the development of insensitivity in a previously susceptible organism. At present this is known to develop only after exposure to the drug. of mercuric chloride. After a small amount of urine had been voided to wash out the urethra, the stream was interrupted with a sterile test tube for the collection of the specimen.

The urine was centrifuged and smears were made and stained by the Gram method. Cultures were made routinely on beef extract broth, blood agar slants or plates adjusted to a $\mathrm{pH}$ of 7.5., and desoxycholate plates. Individual colonies were transplanted to differential sugars for further identification. When the presence of organisms which required special bacteriologic methods was suspected, the necessary conditions of partial or complete anaerobiosis or increased carbon dioxide tension were achieved.

Therapy was usually started as soon as gram-negative bacilli were detected on a smear or culture, without awaiting complete identification. During therapy, cultures were usually made daily. One or more additional cultures were done at least 24 hours after the completion of therapy, before the patient was discharged from the hospital, and a culture was made on each follow-up visit.

\section{In vitro sensitivity (susceptibility ${ }^{4}$ ) tests}

In all cases the susceptibility of the etiologic agents to streptomycin, penicillin, and sulfadiazine was determined in vitro when the organisms were initially isolated. A test tube method was adopted because of its simplicity and convenience. Three milliliters of beef extract broth was placed in each tube, and the tubes were sterilized in an autoclave. Sterile aqueous stock solutions were prepared which contained respectively $2.5 \mathrm{mgm}$. of sulfadiazine, 250 units of penicillin, and 1,000 micrograms ( $0.001 \mathrm{gram})$ of streptomycin per $\mathrm{ml}$. Three series of tubes were arranged in a rack, one series for each of the drugs. One $\mathrm{ml}$. of the stock solution of the chemotherapeutic agent was mixed with the broth in the first tube of the series, and $1 \mathrm{ml}$. of this mixture was transferred to the second tube; $1 \mathrm{ml}$. of the mixture from the second tube was then transferred to the third, and so forth. In order to keep the volume constant, $1 \mathrm{ml}$. was removed from the last tube of the series and discarded. In this fashion were prepared a series of 4 tubes containing graded concentrations

4 The term sensitivity, when applied to the response of organisms to chemotherapeutic agents, may lead to confusion with sensitivity (allergic) of the host. Perhaps susceptibility or inhibitory level is a better term. 
of sulfadiazine ranging from 64 to $1 \mathrm{mgm}$. per $100 \mathrm{ml}$., another series of 4 tubes containing 64 to 1 units of penicillin per ml., and a third series of 6 tubes containing 250 to $0.3 \mu \mathrm{g}$. of streptomycin per ml. A control tube of broth containing no drug was added to each series.

All tubes were inoculated with approximately the same amount of the test organism; colonies were picked from solid media, or a loop of pure broth culture was transferred. The tubes were incubated for 24 hours, and then examined for bacterial growth as evidenced by turbidity. The result was usually obvious on inspection of the tubes. The lowest concentration of the drug which inhibited growth was taken as an index to the susceptibility of the organism.

The predominating organism in each case was tested; in cases of mixed infections most of the other organisms were also tested, either singly or in combination with the predominant organism. Studies were repeated at intervals during the course of therapy. The organism originally isolated was subcultured for comparison with those recovered at various intervals after the initiation of therapy. Therapy with streptomycin was not withheld pending the demonstration of sensitivity of the organism, since one object of the study was the evaluation of the in vitro technique as a means of predicting the efficacy of therapy. In the early stages of the study the concentrations of streptomycin in the media were occasionally varied, so that some results for concentrations of 10 and $100 \mu \mathrm{g}$. per ml., as well as for the standard dilutions, are reported in the tables.

\section{Determinations of streptomycin concentrations in blood and urine}

The method of Price, Nielsen, and Welch was used without modification to determine the concentration of streptomycin in serum and urine (4). Blood samples were drawn at random during the course of therapy; the blood was centrifuged and the serum used undiluted. Single voided specimens of urine, as well as 12 and 24hour total collections, were assayed. All urine specimens were passed through a Seitz filter prior to the determination; preliminary experiments had indicated that no appreciable loss of streptomycin occurred by adsorption on the filter. Urine which was thought to contain a high concentration of streptomycin was tested in a dilution of $1: 50$.

The fluid to be tested was serially diluted in test tubes with a special broth adjusted to $\mathrm{pH} 7.8$. In a second series of tubes the fluid of unknown streptomycin content was replaced by a solution of streptomycin containing $10 \mu \mathrm{g}$. per $\mathrm{ml}$. To each tube in both series $1.5 \mathrm{ml}$. of a 1:100 dilution of a 12-hour growth of Bacillus circulans in broth was added. The tubes were incubated overnight at $37^{\circ} \mathrm{C}$.; the last tube in which no growth occurred was considered the end point. The concentration of streptomycin in the test fluid was determined by comparing the end point of the first series of tubes with that of the second.

\section{Patients}

Forty-five patients received 52 courses of streptomycin for urinary tract infections due to gram-negative bacilli. Seven patients each received 2 courses of the drug. All patients were admitted to the wards of the North Carolina Baptist Hospital ${ }^{5}$ and were treated between March and October, 1946. The youngest patient was 4 years, and the oldest, 74 years of age. In 12 instances the infection had been present 4 weeks or less; in the remaining 40 , symptoms had been present for periods ranging from 1 month to 22 years. As many patients as possible were seen in the Outpatient Department at monthly intervals after discharge; the average duration of follow-up was $2 \frac{1}{2}$ months, and the maximum period was 6 months.

\section{Methods and treatment}

The total daily dose varied from 0.15 to $2.0 \mathrm{gram}$; the individual doses ranged from 25,000 to $333,000 \mu \mathrm{g}$. each and were contained in 1 to $2 \mathrm{ml}$. of sterile physiological saline ${ }^{6}$ or water. The daily dose was divided into 6 equal doses given intramuscularly every 4 hours day and night; the usual course of therapy was $\mathbf{5}$ days, though some patients were treated for as few as 2 days and some as many as 13 days. When the patient's condition permitted, the concentration of streptomycin in the urine was raised by restricting the fluid intake in an attempt to limit the urinary output to approximately 1 liter a day.

Early in the course of the investigation no attempt was made to regulate the $\mathrm{pH}$ of the urine. The importance of adequate alkalinization of urine was soon demonstrated, however, by preliminary in vitro experiments which indicated that the effectiveness of the same concentration of streptomycin was increased 16 -fold by raising the $\mathrm{pH}$ from 5.5 to 8.0. Thereafter, an attempt was made in all cases to increase the $\mathrm{pH}$ of the urine to at least 7.4. The $\mathrm{pH}$ of random voided samples of urine was determined with indicator paper prepared by saturating filter paper in a 0.05 per cent solution of phenol red in 70 per cent methyl alcohol; this method was found to be reasonably accurate within 0.2 of a $\mathrm{pH}$ unit.

\section{RESULTS \\ Susceptibility of organisms}

Fifty-nine strains of 8 species of organisms were isolated. A single organism was demonstrated in 44 cases; in the remaining 8 cases, the infections were mixed and were due to 2 organisms. Those organisms which were inhibited by $16 \mu \mathrm{g}$. or less of streptomycin per ml.-a level which can be attained in the blood-were arbitrarily considered susceptible.

${ }^{5}$ We are greatly indebted to Dr. Fred. K. Garvey, of the Department of Urology, for supervising the complete urologic study of these patients.

- Some evidence has been presented that saline inactivates solutions of streptomycin; water is a better diluent. 
TABLE I

Susceptibility of organisms

\begin{tabular}{|c|c|c|c|c|c|c|c|c|c|c|c|c|c|}
\hline \multirow{4}{*}{ Organisms } & \multicolumn{10}{|c|}{ Before therapy } & \multicolumn{3}{|c|}{ After therapy (drug-fast) } \\
\hline & \multirow{3}{*}{$\begin{array}{c}\text { Number } \\
\text { cases }\end{array}$} & \multicolumn{9}{|c|}{ Streptomycin ( $\mu g$. per $m l)}$. & \multirow{3}{*}{$\begin{array}{c}\text { Number } \\
\text { cases }\end{array}$} & \multicolumn{2}{|c|}{ 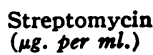 } \\
\hline & & 0.3 & 1 & 4 & $10 *$ & 16 & 64 & $100 *$ & 250 & $>250$ & & & \\
\hline & & \multicolumn{5}{|c|}{ Susceptible } & \multicolumn{4}{|c|}{ Non-susceptible } & & 07 & 8200 \\
\hline $\begin{array}{l}\text { Aerobacter aerogenes } \\
\text { Pseudomonas aeruginosa } \\
\text { Escherichia coli } \\
\text { Alkaligenes fecalis } \\
\text { Klebsiella pneumoniae } \\
\text { Proteus morganii } \\
\text { Streptococcus faecalis } \\
\text { Streptococcus, non-hemolytic }\end{array}$ & $\begin{array}{r}24 \\
22 \\
7 \\
2 \\
1 \\
1 \\
1 \\
1\end{array}$ & $\begin{array}{r}11 \\
2 \\
1\end{array}$ & $\begin{array}{l}3 \\
5 \\
3\end{array}$ & $\begin{array}{l}3 \\
6\end{array}$ & $\begin{array}{l}1 \\
3 \\
1\end{array}$ & $\begin{array}{l}5 \\
5 \\
1 \\
1\end{array}$ & 1 & $\begin{array}{l}1 \\
1\end{array}$ & 1 & $\begin{array}{l}1 \\
1\end{array}$ & $\begin{array}{r}9 \\
11\end{array}$ & $\begin{array}{l}1 \\
2\end{array}$ & $\begin{array}{l}8 \\
9\end{array}$ \\
\hline Total & 59 & 14 & 12 & 9 & 5 & 12 & 1 & 3 & 1 & 2 & 20 & 3 & 17 \\
\hline
\end{tabular}

* These concentrations were used in early experiments only. In some succeeding tables these data are grouped with those for the next higher concentration.

The concentrations of streptomycin required to inhibit the organisms originally isolated are shown in Table I. The susceptibility of different species of gram-negative bacilli and of various strains within the same species varied greatly, but most gram-negative bacilli were susceptible initially to concentrations of streptomycin which can be readily attained in vivo. Of the organisms most frequently isolated, strains of Aerobacter aerogenes were slightly more sensitive than those of Pseudomonas aeruginosa; strains of Escherichia coli were intermediate in susceptibility. In view of the levels of streptomycin which can be attained in blood or urine, the variations in susceptibility to concentrations of streptomycin below $16 \mu \mathrm{g}$. per ml. are of doubtful clinical importance.

The most striking bacteriologic finding in the study was the development of fastness to streptomycin in organisms previously sensitive to the drug. The results of sensitivity tests using strains of organisms obtained after the completion of streptomycin therapy are also shown in Table I. All the organisms were recovered from patients in whom treatment with streptomycin had failed, and the levels recorded represent the maximum degree of resistance observed. Further testing several months later of the available strains of organisms which had been found insensitive to more than $250 \mu \mathrm{g}$. of streptomycin per $\mathrm{ml}$. revealed the following levels of susceptibility:
Concentration of streptomycin

$\begin{array}{cccc}\text { in } \mu \text { g. per ml. } & 2,500 & 10,000 & >10,000 \\ \text { Number of strains } & 4 & 2 & 3\end{array}$

The relation of bacterial fastness to the dose or concentration of streptomycin, the duration of therapy, and other factors will be discussed further below.

Susceptibility to streptomycin of the organisms originally isolated is compared with their sensitivity to sulfadiazine and penicillin in Table II. No correlation was found; organisms resistant to sulfadiazine and penicillin were susceptible to streptomycin. A comparison of the susceptibility of the organisms to sulfadiazine and penicillin was made. Most of the organisms which were refractory to sulfadiazine were found also to be resistant to penicillin, but it should be stated that all of the patients had had an unsuccessful clinical trial with at least one of these drugs before streptomycin was administered.

\section{Comparison of the dose of streptomycin with the concentration in blood and urine}

In Figure 1 the total daily dose of streptomycin is compared with the maximum level attained in the blood. The blood levels varied widely, but in general the blood concentration was found to be proportional to the size of the dose. When the data are plotted in relation to the body weight, a much closer correlation is observed. 
TABLE II

Susceptibility of organisms to streptomycin compared with that to penicillin and sulfadiazine

\begin{tabular}{|c|c|c|c|c|c|c|c|c|c|}
\hline \multirow{3}{*}{ 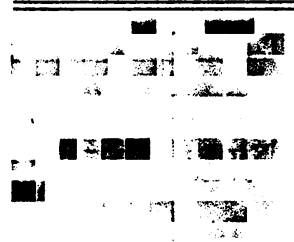 } & \multicolumn{9}{|c|}{ Streptomycin ( $\mu \mathrm{g}$. per $m l$. ) } \\
\hline & 0.3 & 1 & 4 & 10 & 16 & 64 & 100 & 250 & $>250$ \\
\hline & \multicolumn{5}{|c|}{ Susceptible } & \multicolumn{4}{|c|}{ Non-susceptible } \\
\hline $\begin{array}{cr}\text { Sulfadiazine } & 1 \\
\text { (mgm. per cent) } & 4 \\
& 16 \\
64\end{array}$ & $\begin{array}{l}5 \\
7\end{array}$ & $\begin{array}{l}2 \\
6\end{array}$ & $\begin{array}{l}1 \\
3 \\
6\end{array}$ & 4 & $\begin{array}{l}1 \\
1 \\
9\end{array}$ & 1 & 2 & & 2 \\
\hline $\begin{array}{lr}\text { Penicillin } & 1 \\
\text { (units per ml.) } & 4 \\
& 16 \\
& 64\end{array}$ & 12 & 8 & $\begin{array}{l}2 \\
1 \\
8\end{array}$ & 2 & 10 & 1 & $\begin{array}{l}1 \\
1\end{array}$ & & 2 \\
\hline
\end{tabular}

The maximum levels of streptomycin in the urine vary widely in relation to the total daily dose as is shown in Figure 2. The concentration in the urine was usually several times greater than that in the blood. When the maximum urinary
STREPTOMYCIN IN BLOOD

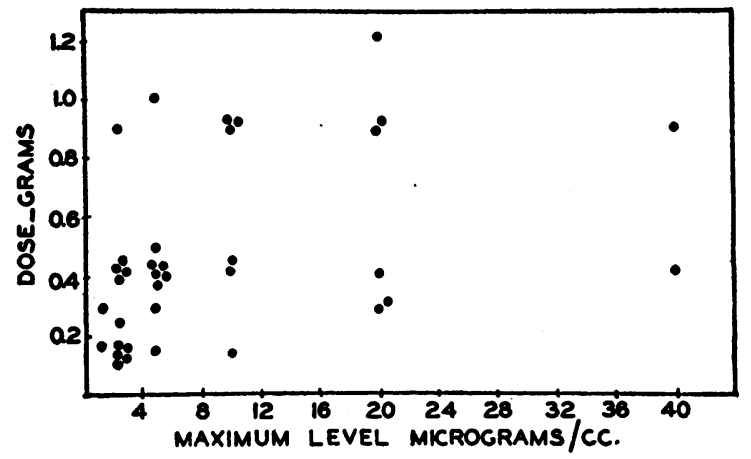

Fig. 1. Comparison of the Maximum Level of Streptomycin in the Blood with the Total DaIly Dose INJeCted INTRAMUSCULARLY

level observed is compared with the daily dose calculated in relation to body weight, the correlation is slightly better.

Since only one of the patients exhibited marked impairment of renal function, the effect of renal

STREPTOMYCIN IN URINE

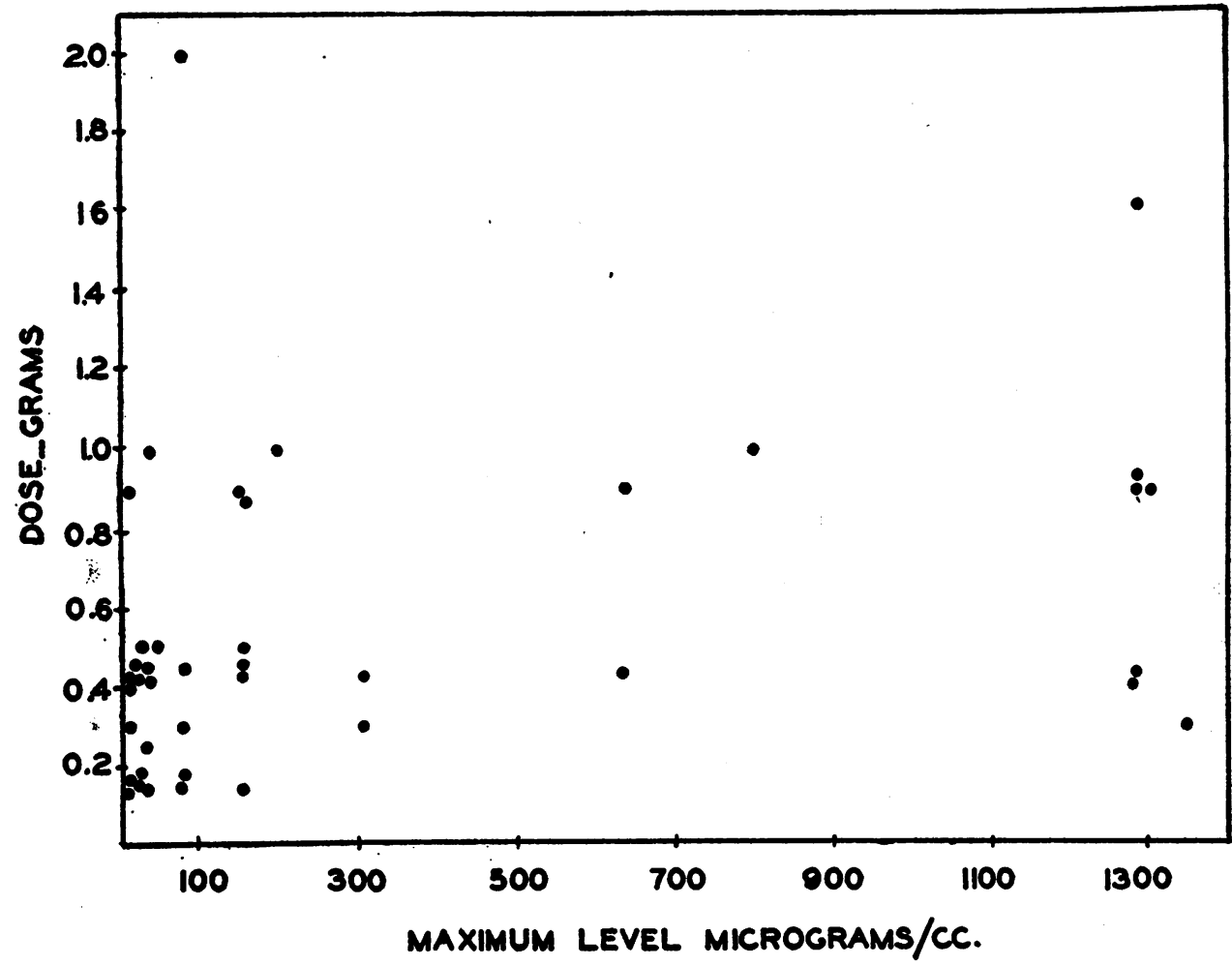

Fig. 2. Comparison of the Maximum Levec of Streptomycin in the Urine with the Total Daily Dose Injected Intramuscularly 
function on the concentration of streptomycin in the urine could not be determined. Alteration of the $\mathrm{pH}$ of the urine did not appear to increase or decrease the rate of streptomycin excretion in the few patients in whom the urinary concentration of the drug was redetermined after the administration of alkali. The greatest factor affecting the urinary concentration of the drug appeared to be the urine volume. In most cases the amount of streptomycin excreted within 24 hours in the urine fell close to the reported average of 65 per cent of the total injected daily dose $(1,5)$.

It appears that a minimum daily dose of 0.6 gram of streptomycin is necessary to assure a blood level of $10 \mu \mathrm{g}$. per ml., and that a dose of 1.5 to 2.0 grams is necessary to raise the blood level above $16 \mu \mathrm{g}$. per $\mathrm{ml}$. With the minimum dose used ( 0.15 gram daily) it was possible to attain a urinary level 5 times that which inhibited susceptible organisms in vitro. The minimum daily dose of streptomycin required to maintain a urinary concentration above $100 \mu \mathrm{g}$. per ml. appeared to be 0.6 gram.

\section{Effectiveness of therapy ${ }^{7}$}

In 29 of the 52 infections ( 56 per cent), the urine became sterile before the completion of therapy.

Relation of susceptibility and streptomycin concentration to the therapeutic results. A comparison of the initial level of susceptibility of the organism with the maximum blood level of the drug attained indicates no correlation between these factors either in the arrested cases (Figure 3 ) or in the therapeutic failures (Figure 3A). In some patients infected with apparently non-susceptible organisms the urine was rendered sterile with low blood levels of streptomycin, whereas therapy failed in other cases when the maximum blood concentration exceeded many times the in vitro level of susceptibility of the organism.

A comparison of the initial level of sensitivity of the organism and the maximum urinary level of streptomycin attained reveals no correlation between these factors for either the arrested cases (Figure 4) or those in which therapy failed (Fig-

7 Unless it is otherwise stated, the results given are based on the cultures made at discharge. The difficulty in differentiating between late relapses and reinfections is thus avoided.

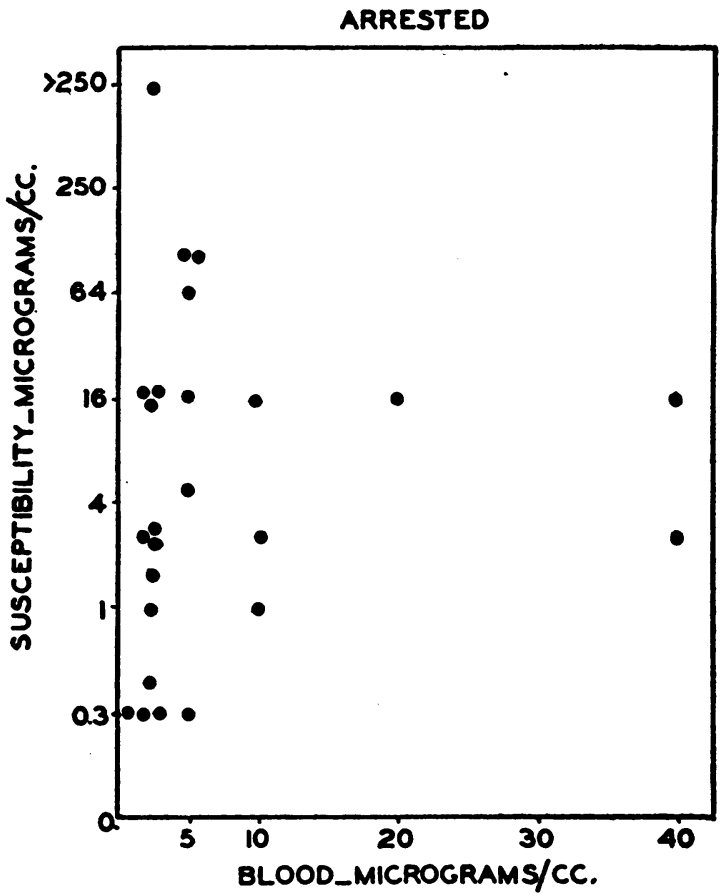

Fig. 3. Comparison of the Degree of Susceptibility to Streptomycin with the Maximum Blood Level of the Drug in the Arrested Cases

FAILED

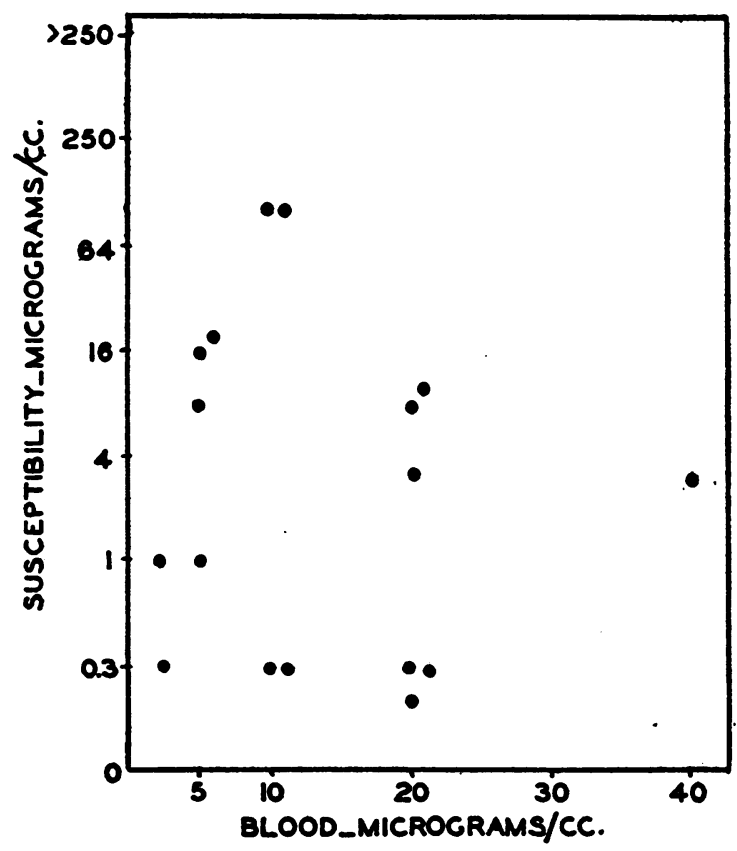

Fig. 3A. Comparison of the Degree of Susceptibility to Streptomycin with Maximum Blood Level of the Drug in the Cases Where Therapy Failed 
TABLE III

Results of therapy in relation to daily dose of streptomycin

\begin{tabular}{l|r|r|c|c|c|c|c|c|c}
\hline \hline & \multicolumn{5}{|c|}{ Grams of streptomycin* } & \multirow{2}{*}{ Total } \\
\cline { 2 - 5 } & $<0.20$ & 0.4 & 0.6 & 0.8 & 1.0 & 1.4 & 1.6 & 2.0 & \\
\hline $\begin{array}{l}\text { Number cases } \\
\text { Arrested }\end{array}$ & 11 & 20 & 3 & 1 & 12 & & 4 & 1 & 52 \\
Failed & 9 & 11 & 1 & 1 & 6 & & 1 & & 29 \\
& 2 & 9 & 2 & & 6 & & 3 & 1 & 23 \\
\hline
\end{tabular}

* For conciseness in this table, intermediate doses are listed as the next highest dose.

ure 4A). Instances of favorable response to therapy were observed when the maximum urinary concentration did not exceed the in vitro level of susceptibility of the organism. On the other hand, failures were observed when the urinary concentration exceeded the in vitro level of sensitivity a hundred times. The greatest number of bacteriologic arrests occurred with a urinary concentration of $100 \mu \mathrm{g}$. per ml.; almost all the immediate
TABLE IV

Results of therapy in relation to duration of treatment

\begin{tabular}{l|r|r|r|r|r|r|r|r|r|r|r|r|r|}
\hline \hline & \multicolumn{7}{|c|}{ Days } & Total \\
\cline { 2 - 7 } & 2 & 3 & 4 & 5 & 6 & 7 & 8 & 9 & 10 & 11 & 12 & 13 & \\
\hline $\begin{array}{l}\text { Number } \\
\text { cases } \\
\text { Failed }\end{array}$ & 4 & 2 & 3 & 17 & 7 & 10 & & 3 & 2 & & 2 & 2 & 52 \\
\hline
\end{tabular}

cures occurred with a concentration of $200 \mu \mathrm{g}$. per $\mathrm{ml}$. of urine.

Other factors affecting the therapeutic results. The total daily dose of streptomycin did not appear to affect the result of therapy as is shown in Table III. The results of therapy at discharge are compared with the total duration of treatment in Table IV. The effectiveness of streptomycin did not seem to be dependent upon the duration of the infection before the institution of therapy. Four chronic infections, 2 of which were mixed,



Fig. 4. Comparison of the Degree of Susceptibility to Streptomycin with the Maxmum Urine Level of the Drug in Arrested Cases 
FAILED



Fig. 4A. Comparison of the Degree of Susceptibility to Streptomycin with the Maximum Urine Level of the Drug in Cases Where Therapy Failed

were treated for 48 hours only; the urine became sterile within 36 hours, and was sterile at discharge.

When the cases are divided into infections of the upper urinary tract (above the bladder) and those of the lower urinary tract (in and below the bladder), the location of the infection is seen to be of little consequence (Table V).

The effectiveness of streptomycin in sterilizing the urine did not seem to be dependent upon the species of the etiologic agent or its original sus-

TABLE $\mathbf{V}$

Results of therapy in upper and lower urinary tract infections with and without complications

\begin{tabular}{|c|c|c|c|c|c|c|c|c|}
\hline & \multicolumn{3}{|c|}{ Uncomplicated } & \multicolumn{3}{|c|}{ With complication } & \multicolumn{2}{|c|}{ Total } \\
\hline & $\begin{array}{l}\text { Up- } \\
\text { per }\end{array}$ & Lower & Total & $\begin{array}{l}\text { Up- } \\
\text { per }\end{array}$ & Lower & Total & $\begin{array}{l}\text { Up- } \\
\text { per }\end{array}$ & Lower \\
\hline $\begin{array}{c}\text { Number } \\
\text { cases }\end{array}$ & 14 & 14 & 28 & 14 & 10 & 24 & 28 & 24 \\
\hline $\begin{array}{l}\text { Arrested } \\
\text { Failed }\end{array}$ & $\begin{array}{r}14 \\
0\end{array}$ & $\begin{array}{r}11 \\
3\end{array}$ & $\begin{array}{r}25 \\
3\end{array}$ & $\begin{array}{r}2 \\
12\end{array}$ & $\begin{array}{l}2 \\
8\end{array}$ & $\begin{array}{r}4 \\
20\end{array}$ & $\begin{array}{l}16 \\
12\end{array}$ & $\begin{array}{l}13 \\
11\end{array}$ \\
\hline
\end{tabular}

ceptibility (Table VI). Of the two most common single etiologic agents, therapy failed in 42 per cent of the infections with $A$. aerogenes and in 55 per cent of those with $P$ s. aeruginosa; $A$. aerogenes was slightly more susceptible in the in vitro test than Ps. aeruginosa. Because of the small number of cases involved, the difference in response is not thought to be significant. Mixed in-

TABLE VI

Results of therapy in relation to susceptibility of infecting organism

\begin{tabular}{|c|c|c|c|c|c|c|c|c|}
\hline \multirow{2}{*}{ Organism } & & \multicolumn{6}{|c|}{ Streptomycin ( $\mu g$. per $m l$. ) } & \multirow{2}{*}{ Total } \\
\hline & & 0.3 & 1 & 4 & 10: & 16 & $>16$ & \\
\hline $\begin{array}{l}\text { Aerobacter } \\
\text { aerogenes }\end{array}$ & $\begin{array}{l}\text { Number } \\
\text { cases } \\
\text { Arrested } \\
\text { Failed }\end{array}$ & $\begin{array}{r}11 \\
6 \\
5\end{array}$ & $\begin{array}{l}3 \\
2 \\
1\end{array}$ & $\begin{array}{l}3 \\
3 \\
0\end{array}$ & $\begin{array}{l}1 \\
0 \\
1\end{array}$ & $\begin{array}{l}5 \\
3 \\
2\end{array}$ & $\begin{array}{l}1 \\
0 \\
1\end{array}$ & $\begin{array}{l}24 \\
14 \\
10\end{array}$ \\
\hline $\begin{array}{c}\text { Pseudomonas } \\
\text { aeruginosa }\end{array}$ & $\begin{array}{l}\text { Number } \\
\text { cases } \\
\text { Arrested } \\
\text { Failed }\end{array}$ & $\begin{array}{l}5 \\
1 \\
4\end{array}$ & $\begin{array}{l}6 \\
2 \\
4\end{array}$ & $\begin{array}{l}3 \\
1 \\
2\end{array}$ & $\begin{array}{l}5 \\
4 \\
1\end{array}$ & & $\begin{array}{l}3 \\
2 \\
1\end{array}$ & $\begin{array}{l}22 \\
10 \\
12\end{array}$ \\
\hline
\end{tabular}


TABLE VII

Results of therapy in cases with and without complication in relation.to susceptibility of infecting organism (Effectiveness of in vitro test in predicting results of therapy)

\begin{tabular}{|c|c|c|c|c|c|c|c|c|c|c|c|c|c|c|c|}
\hline \multirow{3}{*}{$\begin{array}{l}\text { Streptomycin } \\
\text { (ug. per ml.) }\end{array}$} & \multicolumn{7}{|c|}{ Uncomplicated } & \multicolumn{7}{|c|}{ With complication } & \multirow{3}{*}{ Total } \\
\hline & \multicolumn{4}{|c|}{ Susceptible } & \multicolumn{2}{|c|}{$\begin{array}{c}\text { Non- } \\
\text { susceptible }\end{array}$} & \multirow{2}{*}{ Total } & \multicolumn{4}{|c|}{ Susceptible } & \multicolumn{2}{|c|}{$\begin{array}{l}\text { Non- } \\
\text { susceptible }\end{array}$} & \multirow{2}{*}{ Total } & \\
\hline & 0.3 & 1 & 4 & 16 & 64 & $>64$ & & 0.3 & 1 & 4 & 16 & 64 & $>64$ & & \\
\hline $\begin{array}{l}\text { Arrested } \\
\text { Failed }\end{array}$ & 6 & 3 & 6 & $\begin{array}{l}9 \\
1^{*}\end{array}$ & 1 & $\begin{array}{l}2 \\
1\end{array}$ & $\begin{array}{r}27 \\
2\end{array}$ & $\frac{1}{5}$ & 6 & $\begin{array}{l}1 \\
4\end{array}$ & 5 & & 1 & $\begin{array}{r}2 \\
21\end{array}$ & $\begin{array}{l}29 \\
23\end{array}$ \\
\hline Total & & & & 25 & & 4 & 29 & & & & 22 & & 1 & 23 & 52 \\
\hline
\end{tabular}

* Failure was due to mismanagement of therapy.

fections, including the 3 with streptococci, cleared as well as did those due to a single organism.

The effectiveness. of therapy was greatly decreased by the presence of a complication, such as a foreign body (cystostomy tube, urethral catheter, or calculus), obstruction to the urinary flow (hydronephrosis, neurogenic bladder paralysis, or benign prostatic hypertrophy), a source of constant reinfection (prostatitis or external ureterostomy), or impaired renal function. Failures were extremely common in the presence of such complications (Table VII), and with 1 exception were accompanied by the development of drug-fastness, which is discussed further below.

Further analysis of the 23 cases in which therapy was unsuccessful revealed that in 4 cases the poor results could be at least partially attributed

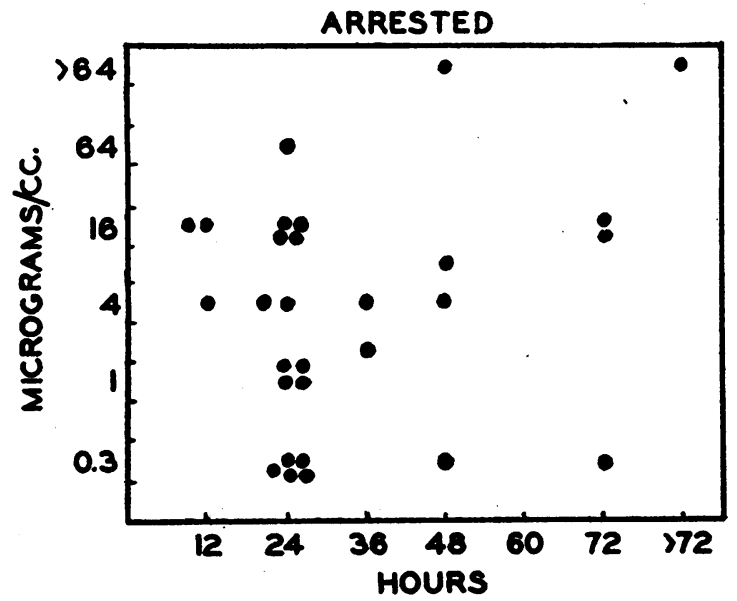

Fig. 5. Comparison of the Degree of Susceptibilty to Streptomycin with the Time Reguired to Sterilize the Urine in the Arrested Cases to failure to alkalinize the urine; complications were present in 2 of these cases. One patient in whom no complication was present was thought to have received an inadequate dose too intermittently, and to represent an instance of mismanagement of therapy. In 1 uncomplicated case the organism isolated before the institution of therapy was not susceptible in vitro.

Factors affecting the rapidity of bacteriologic arrest. In 28 of the 29 arrested cases the urine was sterile by the end of the third day. The rapidity with which sterilization occurred did not seem to be dependent upon the species of bacteria. When the data are plotted on a scatter diagram, it would appear that in general the susceptibility of the organism to streptomycin before therapy is inversely proportionate to the time required for

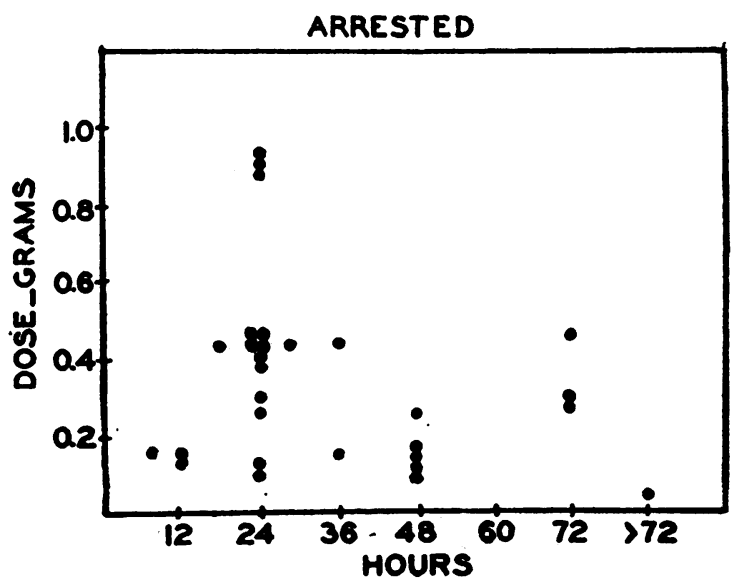

Fig. 6. Comparison of the Total Daily Dose of Streptomycin with the Time Reguired to SteriliZe the Urine in the Arrested Cases 
the urine to become sterile (Figure 5). When the total daily dose of streptomycin is compared with the time required to sterilize the urine, the data appear to indicate that the larger doses cleared the urine more quickly. When the data are plotted in a scatter diagram, however, the correlation between the dosage and the time at which cultures became sterile is less striking (Figure 6).

Accuracy of in vitro test in predicting results of therapy. The results of therapy are compared with the in vitro susceptibility of the organism in Table VII. The results indicate that the in vitro test predicted a favorable response in 24 of the 29 uncomplicated cases, and that this prediction proved to be correct in every case but one. A favorable response which would not have been anticipated occurred in 3 cases out of 5 in which the organisms were classified as non-susceptible. The 2 failures in patients without complications were attributed to mismanagement of therapy-inadequate and intermittent doses-or treatment of nonsusceptible organisms. Only 2 of the patients with complications obtained a favorable response. In the remainder, with 1 exception, the organisms developed drug-fastness. The in vitro test would therefore appear to be useful only in cases without complications.

Follow-up studies. The majority of the patients were followed at least 1 month; the average duration of follow-up was $21 / 2$ months. Of the 29 patients whose infection was arrested at the time of discharge, 15 remained free of infection at the last follow-up examination, and 5 were found to be infected; 9 were not traced. Thus approximately $2 / 3$ of those whose urine became sterile during therapy had sterile cultures and no pyuria when they were reexamined. In the patient with the longest history of infection ( 22 years), the urine was still sterile 6 months after discharge. In 3 of the 5 patients who were found to be reinfected, a different organism was cultured from the urine 3 to 8 weeks after the original infection was cleared up. Two patients whose urine became sterile under therapy were found, 5 and 8 weeks later, again to have infections with the same species of organism, which had the same susceptibility to streptomycin as the original strain; it is not known whether these cases represent reinfections or late relapses.

\section{Fastness}

The development of fastness in the organism was the most common cause of therapeutic failure observed. In 23 instances, bacilluria persisted following completion of a course of streptomycin. The prolongation of therapy did not alter the clinical results, and second courses of therapy after the organism had become fast invariably failed.

The development of fastness to streptomycin did not alter the susceptibility of the organism to other types of therapy, however. Infections with resistant organisms have cleared on subsequent therapy with mandelic acid, for instance, and have cleared without additional chemotherapy when a complicating factor-such as neurogenic bladder paralysis due to poliomyelitis-was removed.

Once an organism became fast, it remained fast. The development of refractoriness only rarely altered the cultural characteristics of the organism.

Factors affecting the development of fastness. Fastness developed much more frequently in the presence of a complicating factor. The fact that the organism became resistant in 3 out of 4 cases of bacteriologic failure in which the urine was not alkalinized suggested the possibility that the $p H$ of the urine might have some effect on the development of fastness. Another possible explanation for failure also was present in each case, however.

The development of fastness apparently bore no relation to the initial susceptibility of the organism (Table VIII). Resistance developed in roughly

TABLE VIII

Initial susceptibility of organisms in relation to development of drug-fastness

\begin{tabular}{l|r|r|r|r|r}
\hline \hline & \multicolumn{2}{|c|}{$\begin{array}{l}\text { Streptomycin } \\
(\mu g . \text { per ml. })\end{array}$} & Total \\
\cline { 2 - 6 } & 0.3 & 1 & 4 & 16 & \\
\hline Number of organisms & 14 & 11 & 10 & 17 & 52 \\
Number developed fastness & 4 & 5 & 4 & 5 & 18 \\
Per cent developed fastness & 29 & 46 & 40 & 30 & 35 \\
\hline
\end{tabular}

30 to 45 per cent of the organisms cultured regardless of the original degree of sensitivity. In 21 of the 23 cases in which the original course of therapy was ineffective, in vitro tests to determine the sensitivity of the causative organism were repeated. In 1 case the organism retained its original susceptibility. In 17 , it was found to be resistant to streptomycin in a concentration of at 
least $250 \mu \mathrm{g}$. per $\mathrm{ml}$. (Table I). In 3 instances the sensitivity decreased by only 1 tube in the in vitro test. A maximum urinary concentration of streptomycin at least 5 times as great as the original in vitro level of sensitivity had been obtained in all patients infected with susceptible organisms.

When the duration of therapy before the development of fastness is plotted against the initial susceptibility, it is seen that, in general, organisms which were inhibited by streptomycin in a concentration of $16 \mu \mathrm{g}$. per ml. became refractory earlier than organisms which were originally not inhibited by this concentration. In the majority of the cases a period of 24 to 72 hours elapsed before the organisms became fast, though, in 1 case, resistance developed in 8 hours. In several instances cultures made 10 to 24 hours after initiation of therapy were sterile, while subsequent cultures revealed resistant organisms. In only 2 instances did susceptible organisms become fast after 72 hours (Figure 7); obstruction was present in both cases, and both patients received small doses of the drug.

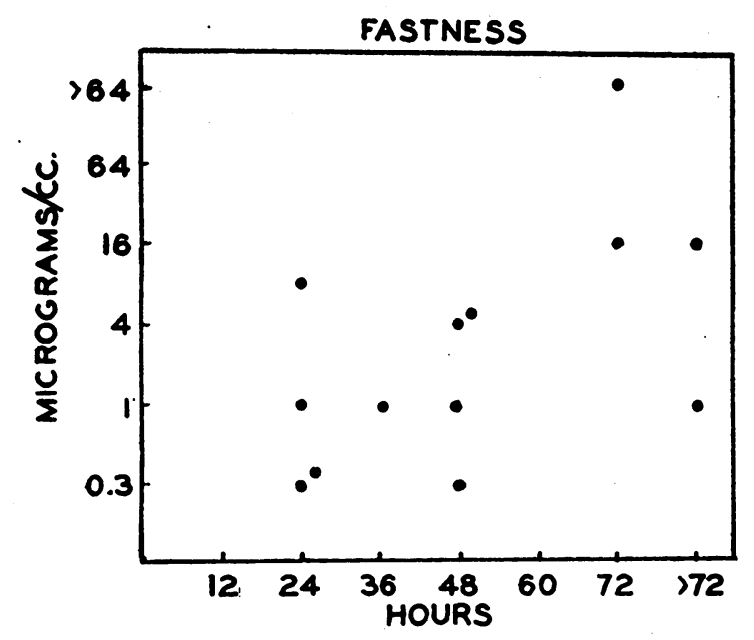

Fig. 7. Comparison of the Initial Degree of Susceptibility to Streptomycin with the Duration of Therapy before the Development of FastNESS

When the duration of therapy before the development of fastness is plotted against the total daily dose of streptomycin, it is seen that some organisms developed resistance in 48 hours in spite of relatively large doses. On the other hand, in the patients receiving the smallest doses, fastness occasionally developed in 72 hours; one such patient was infected with a susceptible organism but also had a complication, while another was infected with an organism which was originally resistant to $16 \mu \mathrm{g}$. of streptomycin per ml. Small doses had been administered for 4 and 5 days to the 2 patients in whom fastness developed after the third day (Figure 8 ) ; both organisms were originally susceptible, but both patients had complications.

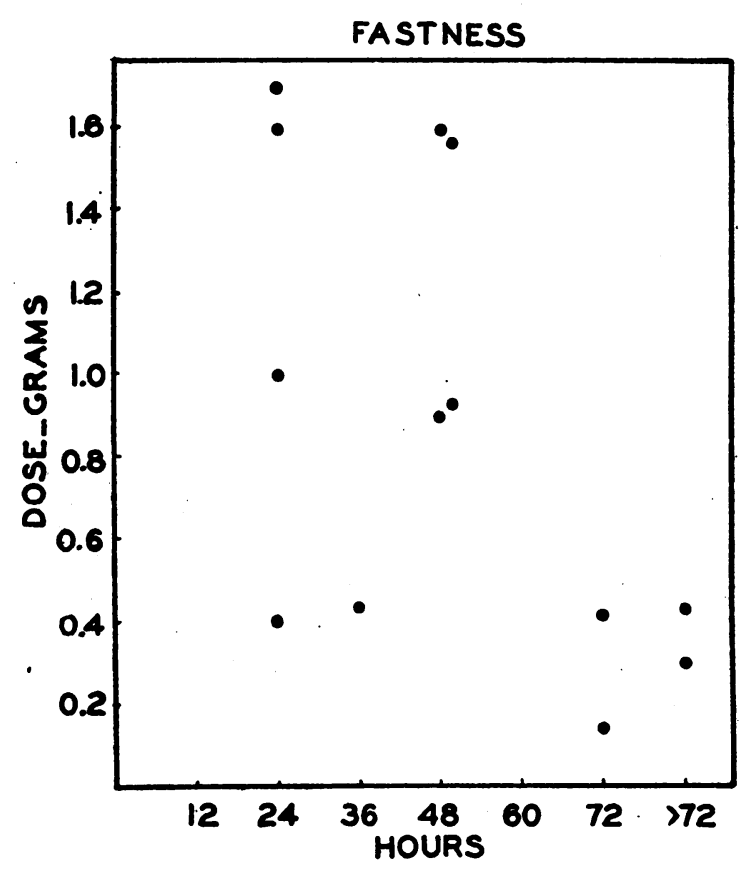

Fig. 8. Comparison of the Total Daily Dose of Streptomycin with the Duration of Therapy beFORE THE DEVELOPMENT OF Fastness

\section{DISCUSSION}

\section{Bacteriologic methods}

Most gram-negative bacilli, when isolated prior to therapy, are susceptible to streptomycin in vitro. The arbitrary classification of organisms into susceptible and non-susceptible strains upon the basis of the in vitro response to streptomycin in concentrations of $16 \mu \mathrm{g}$. or less per ml. is useful; this concentration can be attained in blood or urine with average doses of the drug. The fact that insensitive strains of organisms were occasionally found within the various species of organisms which are usually considered susceptible would justify preliminary in vitro tests in each individual case before administration of the drug.

The in vitro sensitivity test predicted the suc- 
cess of therapy in a sufficient number of uncomplicated urinary tract infections to justify its routine use. The test was not dependable in the presence of complications, however.

Routine in vitro tests before therapy may conveniently be done with only 3 tubes -2 containing dilutions of streptomycin in the range of $16 \mu \mathrm{g}$. per ml., and another containing no drug. The organisms to be tested are introduced into one of the tubes containing streptomycin and into the tube containing no drug, which serves as a negative control; the other streptomycin-containing tube is inoculated with a susceptible organism such as $B$. circulans and serves as a positive control.

Since it is likely that increasing numbers of resistant strains of organisms will be developed, as streptomycin becomes more widely available, a dependable in vitro test for the detection of streptomycin-fast strains before the initiation of therapy will become an important part of the testing and identification of the organism. All organisms recovered from positive cultures after the third day of therapy should be retested for the development of fastness; if a single concentration of streptomycin is used for this purpose, it should probably be either 250 or $1,000 \mu \mathrm{g}$. per $\mathrm{ml}$.

The finding that the sensitivity of gram-negative bacilli to streptomycin bore no relationship to their susceptibility to sulfadiazine and penicillin suggests that these drugs work through different enzyme systems of bacteria. There is a possibility that therapy with streptomycin combined with another chemotherapeutic agent might improve clinical results; further study of this question is justified.

At present there is no substance which can be added to culture media routinely to inhibit the action of streptomycin present in the body fluids of patients under therapy. The development of such a substance ${ }^{8}$ would greatly improve the accuracy of bacteriologic methods for evaluating the effectiveness of therapy, especially in determining the time at which organisms disappear, and might aid in the earlier detection of strains developing fastness, Cultures made after therapy is begun should be incubated at least 7 days, since organisms may grow more slowly then.

\footnotetext{
8 Hydroxylamine hydrochloride is the most promising substance in use at present.
}

We have no explanation for the fact that relatively few strains of Proteus were recovered from the patients in this series.

\section{The fastness of organisms to streptomycin}

Whether the development of streptomycin-fastness is due to a mutation of organisms of a single strain or to the removal of a susceptible strain inhibiting a non-susceptible strain present simultaneously cannot be stated from our data. It is known that the tolerance of cells to a toxic agent increases when they are repeatedly exposed to it. Further study from the bacteriologic point of view with the idea of potentiating the action of streptomycin in its blockage of bacterial enzyme systems, is urgently needed.

Clinically, the development of fastness in organisms is of the greatest importance. The widespread development of streptomycin-fast strains of organisms would reduce the clinical usefulness of the drug. Whether the virulence of the infecting organism is altered by the development of fastness has not been determined definitely. The early detection of resistance will prevent delay in altering therapy, thus conserving the yet small supplies of the drug, and preventing waste of money. The data suggest that the development of resistance may be avoided in some measure by the use of very vigorous therapy, from the beginning, with doses greater than the minimum ones used in this study. Infections should be hit hard when therapy is started, regardless of the duration of the infection.

Since refractoriness to streptomycin is - very likely to develop in the presence of complications, and since it is a permanent characteristic of the organism once it is acquired, it might be advisable, if a complication correctable by surgical measures is present, to use other chemotherapeutic agents preoperatively and to reserve streptomycin for postoperative use. An exception should be made when the use of streptomycin might permit the performance of surgery that otherwise would not be possible.

Because of the evidence suggesting that fastness maý develop in organisms highly susceptible to streptomycin if they are exposed to low concentrations for 3 to 5 days, the use of small doses of the drug to prevent reinfection in arrested cases would not seem justified and may be harmful. Reinfec- 
tion is dependent on the underlying pathologic process, which is not changed by chemotherapy; late relapses or reinfections with new strains are not due to failure of the drug. Streptomycin has worked as effectively in reinfections and relapses due to susceptible organisms as in the initial infections treated; this fact leads us to suspect that the host plays no part in the development of refractoriness of the organism.

\section{Clinical use of streptomycin}

In the light of these studies it would seem justifiable at present to begin streptomycin therapy in cases of urinary tract infection as soon as gramnegative bacilli are demonstrated in smears or cultures, without awaiting complete identification of the organisms and determination of their susceptibility. As streptomycin-fast strains become more widely distributed, however, it would be wise to initiate therapy only after the determination of in vitro sensitivity, especially while the drug is so expensive.

From these studies it is impossible to say whether the concentration of streptomycin in the blood or that in the urine is more important. The arrest of cases of pyelonephritis would suggest that the low concentration which must be present in the glomerular filtrate and which probably is in the range of that of the blood is effective. The greater concentration of the drug in the urine below the kidney tubule is important, however; for the reduction in the number of organisms free in the urine will decrease the opportunity for reinfection of the epithelial surface of the urinary tract. It is probable that the concentration of the drug which is of the greatest importance is that in the capillaries of the kidney and the mucous membrane of the urinary tract, where immune bodies are also found.

The determination of levels of streptomycin in the blood or urine is probably not sufficiently useful to justify its use routinely. Blood and urine levels of the drug should be determined in cases which are not responding to therapy as anticipated.

The smallest daily dose used in this study $(0.15$ gram) was sufficient to maintain blood and urine concentrations which were found effective. Since 0.8 gram of streptomycin was required to maintain with some consistency blood and urine levels of
10 and $100 \mu \mathrm{g}$. per $\mathrm{ml}$. respectively, this dose is suggested as the safe minimum for routine use. In view of the frequent development of fastness, however, we believe that 1.5 grams daily would be a better dose, especially in cases with complications. Therapy should be continued for 3 days. If cultures are still positive, the organism is probably fast. In a few cases cultures became negative after the third day, but this occurrence was not common. If the urine has not become sterile by the third, or certainly the fifth day, the continuation of therapy or the administration of a second course at a later time is not likely to be effective. If the culture is positive after the third day, it is probably wise to change to some other chemotherapeutic agent.

Some factor or factors other than the type of bacteria involved, the susceptibility of the organism to streptomycin, the dose of the drug administered, and the levels attained in the blood and urine are concerned in recovery; one of these factors is undoubtedly the immunity of the host. Several patients with chronic urinary tract infections were found to be hypersensitive to an intradermal test with autogenous vaccine prepared from the strain of bacteria isolated before therapy was begun.

The explanation for the decrease in pyuria and the symptomatic improvement which sometimes occurs in the presence of persistent bacilluria remains obscure. We have not been able to demonstrate decrease in motility or lysis of white blood cells in smears made on slides prepared with dried films of streptomycin in concentrations up to 1,000 $\mu \mathrm{g}$. per $\mathrm{ml}$.

\section{SUMMARY}

1. Streptomycin is the most effective antibiotic available at present for the treatment of urinary tract infections due to gram-negative bacilli.

2. The susceptibility to streptomycin of different species of gram-negative bacilli and of various strains within the same species varies greatly. In vitro testing for susceptibility is useful before therapy is begun and in cases where cultures remain positive after the third day.

3. Streptomycin therapy should be continued at least 3 days; if the patient has not improved after 5 days, the organism has probably become refrac- 
tory and further therapy is not likely to be effective.

4. The occurrence of bacteriologic failures in this series of 52 cases could not be correlated with the susceptibility of the organism in vitro, the daily dose of drug, or the levels of streptomycin in blood and urine.

5. Bacteriologic failures were usually due to the presence of a complication in the urinary tract; in the presence of a complicating factor, the organism rapidly became streptomycin-fast.

6. Fastness to streptomycin develops very rapidly and to a high degree; once acquired, it is a permanent characteristic of the organism.

7. The minimum recommended dose in cases without complications is 0.8 gram daily, given in 6 equally divided intramuscular injections every
4 hours day and night; fewer failures will probably be encountered with a daily dose of 1.5 grams.

\section{BIBLIOGRAPHY}

1. Heilman, D. H., Heilman, F. R., Hinshaw, H. C., Nichols, D. R., and Herrell, W. E., Streptomycin: absorption, diffusion, excretion and toxicity. Am. J. M. Sc., 1945, 210, 576.

2. Keefer, C. S., Streptomycin in infections. J. A. M. A., $1946,132,4,70$.

3. Aikawa, J. K., Gillikin, C. M., Herndon, E. G., Jr., and Harrell, G. T., Simple laboratory aids for the control of streptomycin therapy in general practice. South. M. J., 1947, 40, 141.

4. Price, C. W., Nielsen, J. K., and Welch, H., The estimation of streptomycin in body fluids. Science, 1946, 103, 56.

5. Adcock, J. D., and Hettig, R. A., Absorption, distribution and excretion of streptomycin. Arch. Int. Med., 1946, 77, 179. 